\title{
A prospective comparative evaluation of persistent respiratory morbidity in esophageal atresia and congenital diaphragmatic hernia survivors
}

Saskia J. Gischler ${ }^{a}$, Monique H.M. van der Cammen-van Zijp ${ }^{a, b}$, Petra Mazer ${ }^{a}$, Gerard C. Madern ${ }^{a}$, Nikolaas M.A. Bax ${ }^{a}$, Johan C. de Jongste ${ }^{c}$, Monique van Dijk ${ }^{a}$, Dick Tibboel $^{\mathrm{a}}$, Hanneke IJsselstijn ${ }^{\mathrm{a}}$.

Journal of Pediatric Surgery, 2009:44:1683-1690.

a Department of Pediatric Surgery, Erasmus MC-Sophia Children's Hospital, Erasmus University Medical Center, 3000 CA Rotterdam, The Netherlands

b Division of Pediatric Physiotherapy, Department of Physiotherapy, Erasmus MC-Sophia Children's Hospital, Erasmus University Medical Center, 3000 CA Rotterdam, The Netherlands c Division of Pediatric Respiratory Medicine, Department of Pediatrics, Erasmus MC-Sophia Children's Hospital, Erasmus University Medical Center, 3000 CA Rotterdam, The Netherlands

\section{ABSTRACT}

Purpose

The aim of the study was to compare long-term respiratory morbidity in children after repair of esophageal atresia (EA) or congenital diaphragmatic hernia $(\mathrm{CDH})$.

\section{Patients and methods}

Children were seen at 6,12 , and 24 months and 5 years within a prospective longitudinal follow-up program in a tertiary children's hospital. Respiratory morbidity and physical condition were evaluated at all moments. At age 5 years, pulmonary function and maximal exercise performance were tested.

\section{Results}

In 3 of 23 atresia patients and 10 of 20 hernia patients, bronchopulmonary dysplasia was developed. Seventeen atresia and 11 hernia patients had recurrent respiratory tract infections mainly in the first years of life. At age 5, 25\% of EA and CDH patients measured showed reduced forced expiratory volume in 1 second (z-score $<-2$ ). Both atresia and hernia patients showed impaired growth, with catch-up growth at 5 years in patients with EA but not in those with hernia. Maximal exercise performance was significantly below normal for both groups.

\section{Conclusions}

Esophageal atresia and $\mathrm{CDH}$ are associated with equal risk of long-term respiratory morbidity, growth impairment, and disturbed maximal exercise performance. Prospective follow-up of EA patients aimed at identifying respiratory problems other than tracheomalacia should be an integral part of interdisciplinary follow-up programs. 


\section{INTRODUCTION}

Congenital diaphragmatic hernia $(\mathrm{CDH})$ and esophageal atresia $(\mathrm{EA})$ are both severe congenital anatomical anomalies requiring neonatal surgery and intensive care treatment. Follow-up for children with EA tends to focus on gastrointestinal pathologic condition. ${ }^{1-3}$ Respiratory pathologic condition, however, seems equally important and is widely described as related to the variable amount of tracheomalacia. Abnormal development of the tracheobronchial tree may contribute to tracheomalacia and recurrent atelectasis. ${ }^{4}$ Mild lung function abnormalities after EA repair have been described. ${ }^{5,6}$ Several cross-sectional studies report secondary morbidity. Up to $50 \%$ of EA patients were found to have associated anomalies such as cardiac anomalies and consequently higher morbidity. ${ }^{7} \mathrm{New}$ treatment modalities such as high-frequency oscillation (HFO) ventilation, nitric oxide (NO) administration, and extracorporeal membrane oxygenation (ECMO) have improved survival rates in $C D H$ patients. ${ }^{8-10}$ Evidence is emerging, however, that better survival coincides with a great deal of morbidity. ${ }^{11-17}$ Long-term pulmonary sequelae in $\mathrm{CDH}$ survivors seem to result not only from residual lung hypoplasia with persistent pulmonary hypertension but also from lung injury induced by ventilatory support. ${ }^{18}$ Other risk factors for morbidity are large diaphragmatic defects, ECMO therapy, and patch repair. ${ }^{16}$

We hypothesized that children after repair of EA show the same extent of respiratory pathologic condition as CDH survivors, although probably of a different nature, with different causative mechanisms. The aim of the present study was to describe respiratory morbidity in EA and $\mathrm{CDH}$ patients with respect to baseline characteristics, respiratory tract infections (RTIs), lung function, and maximal exercise performance. In addition, we evaluated gastrointestinal morbidity and physical growth because these factors may influence the main end points with respect to respiratory morbidity. This is the first study to prospectively evaluate respiratory morbidity in EA patients at the age of 5 years.

\section{Methods}

This longitudinal, observational, prospective, cohort study consists of repeated measurements at 6,12 , and 24 months and at 5 years.

\section{Setting}

The facility used for the study was the Pediatric Surgical Department of the Erasmus MC-Sophia Children's Hospital, Rotterdam, the Netherlands. This is the only tertiary academic facility in the Southwestern part of the Netherlands equipped for all major surgical specialties. The referral area has 4 million inhabitants with 44,000 newborns annually. 
Since 1999, a multidisciplinary team -consisting of a consultant senior pediatric surgeon, pediatricians, psychologists, a pediatric physiotherapist, nurses, and a social worker- runs a follow-up program for children born with a major anatomical malformation and their families. A clinical geneticist was added to the team in 2004. The program aims to reduce the overall morbidity associated with these malformations, in particular, the index diagnoses as described by Ravitch. ${ }^{19}$

\section{Patients}

All 68 patients with EA and CDH admitted to the ICU of our department within 7 days after birth from January 1999 to February 2003 were eligible for this study. For the present study, we excluded data from 4 patients having infections and growth impairment as a result of a major syndromal or chromosomal anomaly itself $(E A, n=3$, 2 Down's syndrome and 1 undefined; $C D H, n=1$, Wolf-Hirschhorn syndrome). Data of the 16 children who died within 6 months were excluded as well. Five families did not participate in our follow-up program. Thus, 43 children ( $82.7 \%$ of survivors) completed a 5-year follow-up (Figure 1).

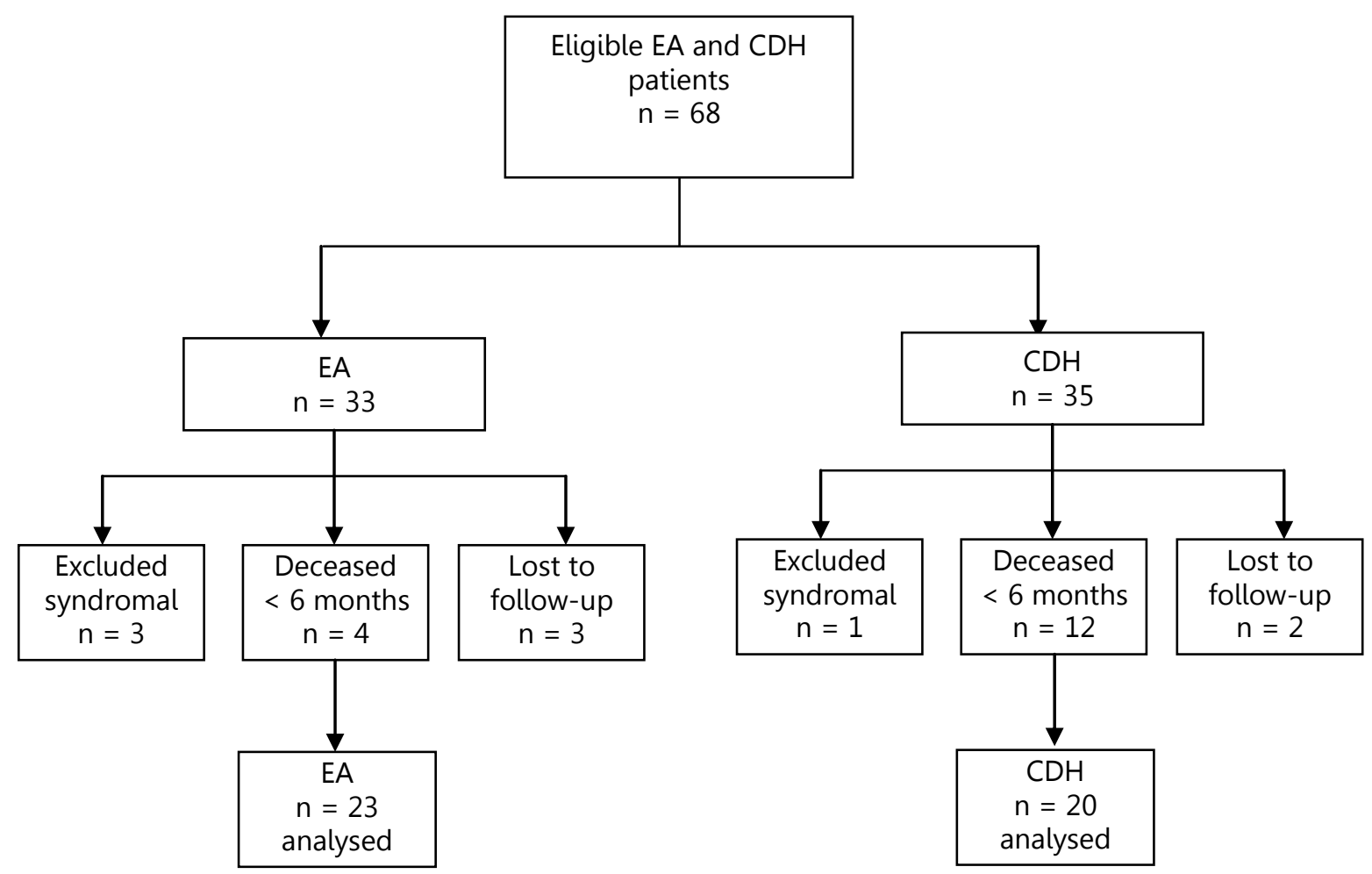

Figure 1 Flowchart showing group composition 


\section{Procedure}

The Erasmus MC ethical review board agreed with the study, and written parental informed consent was obtained for all subjects. Demographic and medical data were collected prospectively from the first day of admission. A clinical geneticist routinely evaluated major chromosomal, syndromal and cerebral abnormalities during admission. By protocol, the children were seen at ages 6, 12, and 24 months and 5 years, corrected for gestational age. Age for the final evaluation ranged from 5 to 6.5 years.

\section{General aspects}

At each time-point, a pediatrician performed a full physical examination including neurologic examination according to the method of Touwen. ${ }^{20}$ A senior pediatric surgeon evaluated specific pediatric surgical issues. Weight and height were measured, and body mass index (BMI) was calculated. Growth data for the Dutch population served as reference values ${ }^{21,22}$ and standard deviation scores (SDS) were calculated using Growth Analyser version 3.5 (Dutch Growth Foundation, Rotterdam, The Netherlands). Reference values for Dutch children of Moroccan or Turkish origin were used if applicable. $^{23,24}$

\section{Respiratory morbidity}

The incidence and severity of bronchopulmonary dysplasia (BPD) were recorded according to the diagnostic criteria of Jobe and Bancalari. ${ }^{25}$

At each time-point, therapeutic and prophylactic courses of antibiotic treatment, use of inhaled bronchodilators and steroids, and readmissions for RTI were recorded. We recorded numbers of RTI during the first, the second, and the third to fifth years, respectively. At the age of 5 years, 38 children (EA patients, $n=20$, and CDH patients, $\mathrm{n}=18$ ) performed pulmonary function tests as follows: we obtained flow-volume curves before and after bronchodilation with $400 \mu \mathrm{g}$ of salbutamol and measured the fraction of exhaled $\mathrm{NO}\left(\mathrm{FE}_{\mathrm{NO}}\right)$. Flow-volume curves were measured on a Masterscreen electronic spirometer (Jaeger, Würzburg, Germany). Forced expiratory volume in 1 second $\left(\mathrm{FEV}_{1}\right)$ was expressed as percentage predicted. Fraction of exhaled NO was measured online according to guidelines from the European Respiratory Society and American Thoracic Society using the NIOX analyzer (Aerocrine, Solna, Sweden). ${ }^{26}$

\section{Maximal exercise performance}

At 5 years, the children performed a graded, maximum exercise test using a motordriven treadmill (En Mill, Enraf Nonius, Rotterdam, the Netherlands) programmed for increases in angle of inclination and speed according to the Bruce protocol. ${ }^{27}$

The children were encouraged to perform to voluntary exhaustion. The maximal endurance time (in minutes, one decimal) served as criterion of exercise capacity, with 
SDS based on recently established reference values for healthy Dutch children (personal communication, van der Cammen-van Zijp, May 2008). Before, during, and at 2 and 5 minutes after the test, children's heart rate and transcutaneous oxygen saturation were monitored with a pulse oximeter (MARS [motion artifact system], type 2001, Respironics Novametrix, Murrysville, Pa). Heart rate of at least 185 beats per minute or loss of coordination was considered to indicate maximal performance. ${ }^{28}$

\section{Gastrointestinal morbidity}

Children were evaluated for gastroesophageal reflux (GER) by barium swallow x-ray and $\mathrm{pH}$-metry as previously described by Bergmeijer. ${ }^{29,30}$ Gastrointestinal symptoms, use of medication, surgical treatment of reflux, and consultation of a dietician were recorded as well.

\section{Data analyses}

Descriptive statistics were calculated for baseline characteristics and outcome variables. We performed group comparisons with the Mann-Whitney $U$ test. Growth parameters and SDS maximal endurance time were compared with the reference values using t-tests for independent samples (1-tailed). Statistical significance was accepted at $5 \%$ level. SPSS 15.0 for Windows (SPSS, Chicago, Ill) was used for data analyses.

\section{RESULtS}

Baseline characteristics for both groups of children are shown in Table 1. All CDH patients were born after a gestational age of at least 36 weeks; 4 EA patients were born before 36 weeks of gestation at 28, 29, 31, and 33 weeks, respectively. All but one EA children underwent primary anastomosis via a lateral thoracotomy within 48 hours. One patient had a type A long gap atresia and underwent delayed primary anastomosis after 3 months. Bronchoscopic evaluation of tracheomalacia during the initial repair was not routinely performed. In 15 of the 20 children with $\mathrm{CDH}$ (75\%), the diaphragmatic defect was repaired with a Gore-Tex patch (WL Gore and Associates, Flagstaff, Ariz). Only one child had a right-sided $\mathrm{CDH}$ (5\%). Diaphragmatic repair was by subcostal laparotomy in all cases.

In neither group complex heart defects were found. For both groups, the major impact of morbidity was during the first year of life; hospital admissions occurred mainly in the first 6 months and surgical interventions within the first year. Surgical interventions in EA patients comprised mainly dilations of anastomotic esophageal strictures (in $70 \%$ of EA patients, $\mathrm{n}=16$, median 2 per patient, range 0 - 9) and Nissen fundoplications $(\mathrm{n}=8,34.8 \%)$. Aortopexies had not been performed. 
Table 1 Baseline characteristics distinguished by CA subgroup

\begin{tabular}{|c|c|c|}
\hline & EA & CDH \\
\hline & $\mathrm{n}=23$ & $\mathrm{n}=20$ \\
\hline Boys, n (\%) & $15(65.2)$ & $12(54.5)$ \\
\hline Gestational age, mean (SD), wk & $37.2(3.5)$ & $39.2(1.5)$ \\
\hline Birth weight, mean (SD), kg & $2.7(0.8)$ & $3.4(0.3)$ \\
\hline Patients without additional (major or minor) CA, $\mathrm{n}(\%)$ & $5(21.7)$ & $12(60.0)$ \\
\hline Patients with 1 or more additional major $\mathrm{CA}, \mathrm{n}(\%)$ & $6(26.1)$ & $3(15.0)$ \\
\hline Patients with 1 or more additional minor CA, $\mathrm{n}(\%)$ & $14(60.9)$ & $5(25.0)$ \\
\hline Patients with cardiac anomaly, n (\%) (ASD, VSD, Coarctation of aorta) & $4(17.4)$ & $2(10.0)$ \\
\hline Admission in $1^{\text {st }} 24$ mo, median (range), d & $60.0(11-181)$ & $67.5(15-192)$ \\
\hline Surgical interventions in $24 \mathrm{mo}$, median (range), $\mathrm{n}$ & $5(1-11)$ & $3(1-6)$ \\
\hline Ventilatory support, median (range), d & $3.5(1-44)$ & $19.5(2-62)$ \\
\hline Supplemental oxygen, median (range), d & $6.0(1-77)$ & $37.5(3-83)$ \\
\hline Patients with additional medical problems at discharge, $\mathrm{n}(\%)$ & $20(86.9)$ & $18(90.0)$ \\
\hline Patients with additional medical problems at 5 y, n (\%) & $21(91.3)$ & $18(90.0)$ \\
\hline Additional medical problems per patient at discharge, median (range) & $2(0-12)$ & $2(0-6)$ \\
\hline Additional medical problems per patient at $5 \mathrm{y}$, median (range) & $2(0-7)$ & $2(0-10)$ \\
\hline
\end{tabular}

CA: congenital anomaly, ASD: atrial septal defect, VSD: ventricular septal defect

Additional medical problems at discharge varied from GER ( $n=21 \mathrm{EA} ; \mathrm{n}=18 \mathrm{CDH})$ to atopic eczema and were mainly (> $80 \%$ for each group) related to the primary congenital anomaly. At discharge, 21 (87\%) of EA patients and all CDH patients received medication. These figures had dropped to $43.5 \%$ and $23.8 \%$ at the age of 5 years, respectively.

\section{Respiratory morbidity}

All EA patients had been ventilated conventionally. Three children (13\%) with severe tracheomalacia developed BPD (Table 2), and bronchoscopy was performed only in these 3 patients. None of the EA patients received ECMO treatment.

Eight $\mathrm{CDH}$ patients (40\%) were primarily ventilated with $\mathrm{HFO}$ and had been converted to conventional ventilation before surgical closure of the diaphragm. Four (33.3\%) of the conventionally ventilated $\mathrm{CDH}$ patients were later converted to HFO ventilation. Venoarterial ECMO was performed in $11 \mathrm{CDH}$ patients (55\%), starting at a median age of 13 (range 5 - 265) hours. Extracorporeal membrane oxygenation was discontinued after a median of 168 (72 - 459) hours.

Routine vaccination against respiratory syncytial virus and/or influenza was not performed. 


\begin{tabular}{|c|c|c|c|}
\hline & & EA & $\mathrm{CDH}$ \\
\hline & & $n=23$ & $n=20$ \\
\hline \multirow[t]{4}{*}{ Patients with BPD, n (\%) } & none & $19(82.7)$ & $8(40.0)$ \\
\hline & mild & $1(4.3)$ & $2(10.0)$ \\
\hline & moderate & $1(4.3)$ & $2(10.0)$ \\
\hline & severe & $2(8.7)$ & $8(40.0)$ \\
\hline Total number of RTI in 5 yrs, median (range) & & $9(0-27)$ & $7(0-17)$ \\
\hline Patients with > 5 RTI in 5 years, $\mathrm{n}(\%)$ & & $17(73.9)$ & $11(55.0)$ \\
\hline Number of patients admitted for RTI in 5 years, median (range) & & $0(0-4)$ & $0(0-1)$ \\
\hline \multirow[t]{4}{*}{ Number of therapeutic courses of antibiotics for RTI, median (range) } & & $3.0(0-17)$ & $3.0(0-8)$ \\
\hline & 1st year & $1.0(0-6)$ & $1.0(0-4)$ \\
\hline & 2nd year & $1.0(0-4)$ & $1.0(0-3)$ \\
\hline & $3-5$ years & $0.0(0-10)$ & $0.0(0-3)$ \\
\hline \multicolumn{4}{|l|}{ Patients treated with prophylactic antibiotics for RTI, n (\%) } \\
\hline & 1st year & $3(13.0)$ & 0 \\
\hline & 2nd year & $5(21.7)$ & $3(15.0)$ \\
\hline & $3-5$ years & $6(26.1)$ & 0 \\
\hline Use of bronchodilators, n (\%) & & $6(26.1)$ & $5(25.0)$ \\
\hline Use of inhaled steroids, n (\%) & & $2(8.7)$ & $2(10.0)$ \\
\hline $\mathrm{FEV}_{1}$ before bronchodilation, mean \% predicted (range) & & $85(69-118) n=12$ & $91(72-122) n=8$ \\
\hline Patients with abnormal FEV $($ Z-score < -2), n (\%) & & $3(25.0)$ & $2(25.0)$ \\
\hline $\mathrm{FE}_{\mathrm{NO}}$, median parts-per-billion (range) & & $9.0(5.0-20.4)$ & $5.2(2.8-10.0)$ \\
\hline
\end{tabular}


Table 2 gives details of the respiratory morbidity encountered during the 5 years of follow-up. Both EA patients born before 30 weeks of gestation developed BPD; only one of them had recurrent RTI. Nine (81.1\%) of 11 ECMO-treated CDH patients and one other developed moderate or severe BPD. Of these 10, 5 (50\%) had recurrent RTI. Recurrent RTI were also reported in $6 \mathrm{CDH}$ patients $(60 \%)$ who had absence of or only mild BPD. One prematurely born EA patient and both $\mathrm{CDH}$ patients with a cardiac anomaly developed BPD. None of them had recurrent RTI.

Hospitalizations for RTI were rare. Median numbers of RTI are relatively low but show wide ranges in both groups.

Spirometry before and after bronchodilation was initiated in 38 patients at 5 years; 5 patients were not examined because of parental refusal $(n=2)$, for practical reasons $(n=2)$, or because of mental retardation $(n=1)$. Most patients, however, failed to perform reproducible flow-volume curves. Forced expiratory volume in 1 second and $\mathrm{FE}_{\mathrm{NO}}$ were the only 2 reliably obtained lung function parameters (Table 2). In both groups, $25 \%$ ( $n=12 \mathrm{EA}, 8 \mathrm{CDH}$ ) of patients had abnormally low percentage of predicted of $\mathrm{FEV}_{1}$. The median $\mathrm{FE}_{\mathrm{NO}}$ was within the predicted range for $(n=9) \mathrm{EA}$ patients $(9.0$ parts-per-billion) and in the lower range of normal for $(n=9) \mathrm{CDH}$ patients (5.2 partsper-billion). ${ }^{31}$

\section{Maximal exercise performance}

One EA patient and $2 \mathrm{CDH}$ patients could not perform the maximal exercise test because of neurologic underlying disease such as cerebral palsy. Thus, 22 EA patients and $18 \mathrm{CDH}$ patients performed the exercise test. Reliable results could not be obtained for 6 EA patients for the following reasons: no maximal exercise performance reached $(n=3)$; balance problems $(n=2)$; and poor concentration $(n=1)$. Results for 2 of the $\mathrm{CDH}$ patients were unreliable because of balance problems or unwillingness to perform maximally ( $\mathrm{n}=1$ for each reason).

Both in EA ( $n=16)$ and $C D H(n=16)$ patients, the maximal exercise tolerance was significantly below the norm (mean SDS endurance time, $-0.60 ; p=0.02$, and -0.84 ; $p=0.012$, respectively). One EA patient (6.3\%) and $2 \mathrm{CDH}$ patients (12.5\%) had an abnormally low maximal exercise tolerance (ie, maximal endurance time SDS $<-2$; not significant). The median (range) heart rate at maximal exercise was 181 (194 - 148) and 191 (207 - 146) beats per minute for the EA and CDH group, respectively. Two EA patients $(12.5 \%)$ had a decreased oxygen saturation (ie, $\leq 94 \%$ ) at maximal exercise (94 and $93 \%$, respectively). This phenomenon was not observed in any of the $\mathrm{CDH}$ patients. 
a

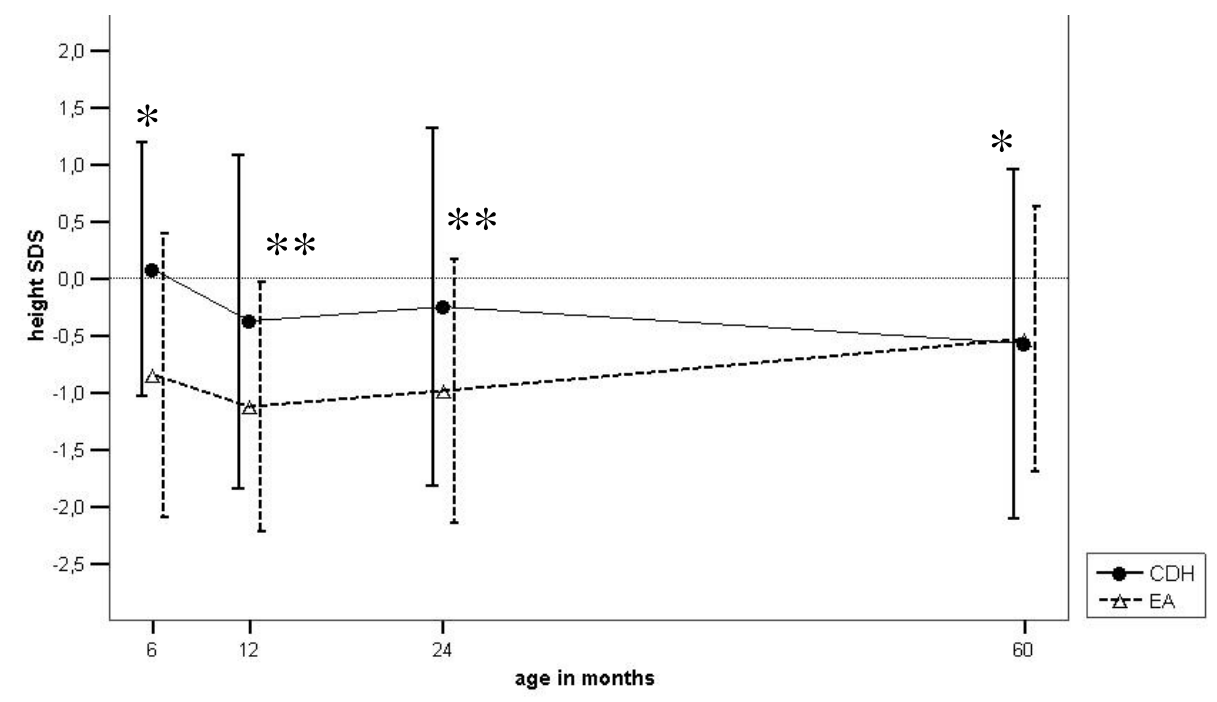

b

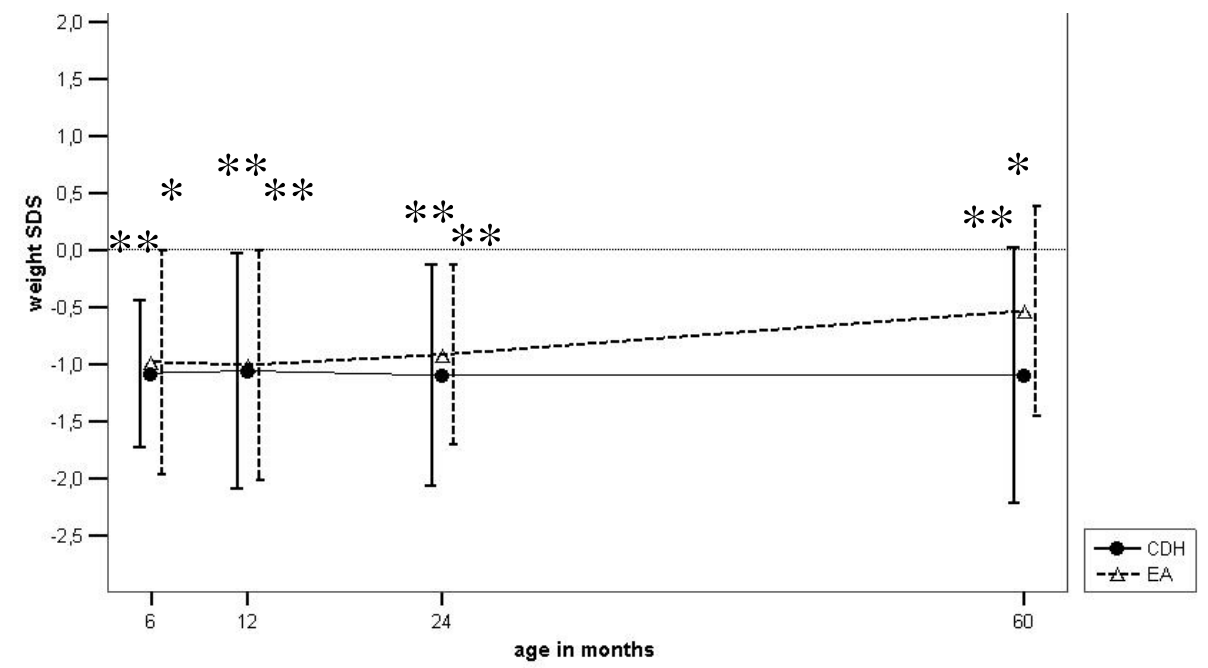

C

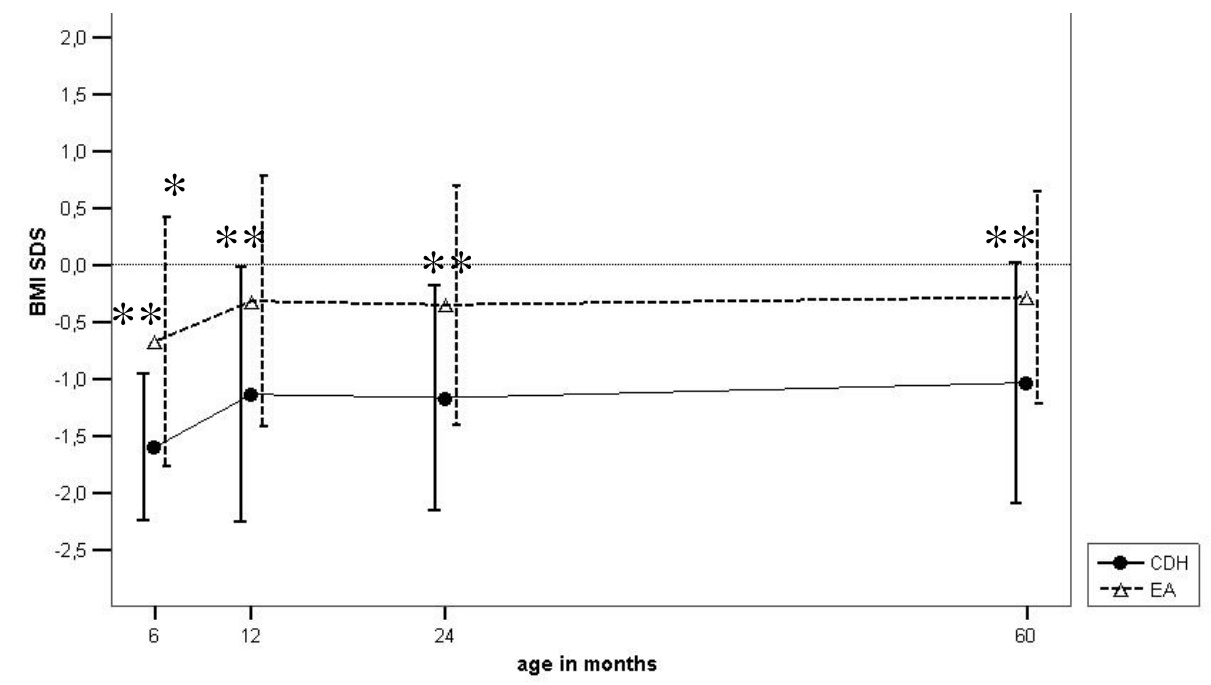

Figure 2(a, b, and c) Diagram representing the mean (SD) for height (a), weight (b), and BMI (c) across time in $C D H$ and EA patients. Circles and solid lines represent $C D H$; open triangles and dashed lines represent $E A$. * signals significant deviation from the Dutch norm at the $5 \%$ level $(p \leq 0.05)$, ** signals significant deviation from this norm at the $0.1 \%$ level ( $p \leq 0.001)$ 


\section{Gastrointestinal morbidity}

In both groups, 20 children were treated conservatively with antacids and prokinetic drugs initially. Thirteen EA patients and $11 \mathrm{CDH}$ patients also received an acid secretion inhibitor. Eight EA patients (34.8\%) and $7 \mathrm{CDH}$ patients (35\%), respectively, underwent a Nissen fundoplication. For those patients who were treated conservatively, the median (range) duration of treatment of GER was 23.11 (0 - 71.7) and $8.0(0$ - 64.9) months in EA and $\mathrm{CDH}$, respectively. Patients with EA who underwent a Nissen fundoplication had a median number of $9.5 \mathrm{RTI}$ in 5 years (range, 0 - 23) vs 7 (3 - 24) for those treated conservatively (NS). Corresponding figures for the $\mathrm{CDH}$ patients are $9(1-17)$ vs 7 $(0-14)$ (NS). There was no significant difference in RTI before or after the Nissen fundoplication.

A dietician was consulted for 8 patients in each group.

\section{Physical growth}

Data at 6, 12, 24, and 60 months for both groups are shown in Figure 2. At 5 years of age, EA patients seemed to catch up in weight, concomitant with an increase in height (Figure $2 \mathrm{~b}$ and $\mathrm{a}$ ). The BMI SDS was constant after the first year of life for both groups but reached a higher level for EA patients (Figure 2c).

Extracorporeal membrane oxygenation-treated $\mathrm{CDH}$ patients had a significantly lower height at 6 months, 12 months, and 5 years ( $p=0.02,0.04$, and 0.04, respectively), lower weight at 12 months and 5 years ( $p=0.02$ and 0.02 , respectively), and lower BMI at 12 months of age $(p=0.05)$ than non-ECMO-treated $C D H$ patients.

\section{Discussion}

We prospectively evaluated respiratory morbidity and factors interrelating with pulmonary disease during the first 5 years in 2 groups of children born with major congenital anatomical malformations of the respiratory tract: EA and $\mathrm{CDH}$. Both groups showed recurrent respiratory tract infections, abnormally low $\mathrm{FEV}_{1}$ in $25 \%$ of patients, no increase of $\mathrm{FE}_{\mathrm{NO}}$ levels, and decreased maximal exercise tolerance. In addition, a high incidence of GER and impaired physical growth were observed in both groups.

Tracheomalacia associated with EA occurs frequently and may lead to respiratory insults. ${ }^{32}$ Less frequent are RTIs, wheezing, and cough; these findings mainly are derived from studies using a cross-sectional design. ${ }^{33-36}$ Results, especially regarding RTIs, therefore may have been influenced by recall bias. Dudley and Phelan ${ }^{37}$ retrospectively evaluated 192 EA survivors and found that 78 children had experienced more than 3 episodes of bronchitis per year in the first 3 years of life. More recent, Malmström et $\mathrm{al}^{34}$ 
showed that $41 \%$ of adolescents after repair of EA still had respiratory symptoms, and $52 \%$ had ever had pneumonia or wheezing. Pneumonia in the first years of life may give rise to mild lung function abnormalities later in life. ${ }^{38}$ Our prospectively collected data are consistent with these findings. In addition, we showed that these problems might negatively affect maximal exercise tolerance. Only 3 EA patients with severe tracheomalacia required prolonged ventilation and developed BPD, whereas 10 (50\%) $\mathrm{CDH}$ patients, mainly those treated with ECMO, had moderate to severe BPD according to criteria of Jobe and Bancalari. ${ }^{25}$ We assume, therefore, that different mechanisms are involved in persisting respiratory morbidity. In $\mathrm{CDH}$ patients, the susceptibility of the hypoplastic lungs for artificial ventilatory support is well documented. ${ }^{13,39,40}$

In both groups, the frequency of RTI at any measurement moment did not differ between children who underwent a Nissen fundoplication for GER or those who were treated conservatively. We assume that reflux in these patients is not a major contributor to RTI.

Interestingly, hospital admissions for RTI were hardly needed, and therapeutic antibiotic courses had not always been prescribed. This suggests that many RTIs showed a relatively mild course and were of nonbacterial origin.

As sample sizes were limited and numbers of possible contributing factors large, we did not perform regression analysis to predict respiratory morbidity. Still, we evaluated several factors that might have contributed to RTI. Being rare in either group, cardiac anomalies did not seem to influence incidences of RTI within the first 5 years. Because $50 \%$ to $60 \%$ of $\mathrm{CDH}$ patients showed recurrent RTI irrespective of BPD, we assume that extrapulmonary factors may be involved as well. Most patients in either group had gastrointestinal problems and impaired physical growth. These factors may well contribute to increased susceptibility for RTI. Nevertheless, the impact of gastrointestinal problems on RTI in EA patients remains inconclusive so far. ${ }^{34,37,38}$

Pulmonary function testing proved problematic. For no more than half of the patients $(n=20)$, we could interpret $\mathrm{FEV}_{1}$ before bronchodilation. This revealed airflow obstruction in $25 \%$ of them. From the literature, it appears that pulmonary function testing was successful in $40 \%$ to $83 \%$ of 5 -year-old children. ${ }^{41}$

Fraction of exhaled $\mathrm{NO}$ is known to be associated with eosinophilic airway inflammation. ${ }^{31,42}$ Almost all patients in the present study had normal $\mathrm{FE}_{\mathrm{NO}}$ levels, in line with findings by Malmström et al. ${ }^{34}$ The $\mathrm{FE}_{\mathrm{NO}}$ level was increased in only one $\mathrm{CDH}$ patient, who showed an atopic constitution. Low or normal $\mathrm{FE}_{\mathrm{NO}}$ levels have also been described in children with bronchopulmonary dysplasia, ${ }^{25}$ which might explain the lower median $\mathrm{FE}_{\mathrm{NO}}$ in the $\mathrm{CDH}$ patients. 
Both EA and $\mathrm{CDH}$ patients showed lower maximal exercise tolerance compared with recently established reference values for healthy Dutch children (personal communication, Van der Cammen-van Zijp). Persistent respiratory morbidity and impaired growth may contribute to this phenomenon.

In spite of gastrointestinal and nutritional morbidity, especially in the first year for EA patients, only $13 \%$ of parents consulted with a dietician during the child's first year of life. For the $\mathrm{CDH}$ patients, failure to thrive remained a problem over time. Lack of catchup growth was mainly seen in ECMO-treated CDH patients. We assume that they have more severe lung hypoplasia requiring intensive work of breathing. Patch repair, GER, and recurrent RTI may also contribute, but our data do not allow for hard conclusions. Attempts should be undertaken to improve energy intake as work of breathing may require a higher energy intake in $\mathrm{CDH}$ and, to a lesser extent, EA patients.

Multidisciplinary follow-up of surgical newborns has hardly been performed so far but has recently been advocated by the American Academy of Pediatrics for CDH patients. ${ }^{43}$ The groups of Muratore and Friedman, ${ }^{15-17}$ however, have reported retrospectively collected data on pulmonary, gastrointestinal, and neurodevelopmental morbidity in $\mathrm{CDH}$ patients up to 3 years of age in a multidisciplinary follow-up clinic. It appeared that these showed continued pulmonary and gastrointestinal morbidity over the years, such as the $\mathrm{CDH}$ patients in the present study, who show the same pathologic condition up to the age of 5 years.

In conclusion, both EA and $\mathrm{CDH}$ patients are at risk for long-term respiratory morbidity, disturbed maximal exercise performance, and growth impairment. Prospective evaluation of EA patients aimed at identifying other respiratory problems than tracheomalacia should be an integral part of postoperative interdisciplinary follow-up programs. 


\section{REFERENCES}

1. Cimador M, Carta M, Di Pace MR, et al. Primary repair in esophageal atresia. The results of long term follow-up. Minerva Pediatr, 2006;58:9-13.

2. Lindahl $H$, Rintala R. Long-term complications in cases of isolated esophageal atresia treated with esophageal anastomosis. J Pediatr Surg, 1995;30:1222-1223.

3. Tomaselli V, Volpi ML, Dell'Agnola CA, et al. Long-term evaluation of esophageal function in patients treated at birth for esophageal atresia. Pediatr Surg Int, 2003;19:40-43.

4. Usui $N$, Kamata $S$, Ishikawa $S$, et al. Anomalies of the tracheobronchial tree in patients with esophageal atresia. J Pediatr Surg, 1996;31:258-262.

5. Agrawal L, Beardsmore CS, MacFadyen UM. Respiratory function in childhood following repair of oesophageal atresia and tracheoesophageal fistula. Arch Dis Child, 1999;81:404-408.

6. Chetcuti P, Phelan PD, Greenwood R. Lung function abnormalities in repaired oesophageal atresia and tracheo-oesophageal fistula. Thorax, 1992;47:1030-1034.

7. Bouman NH, Koot HM, Hazebroek FW. Long-term physical, psychological, and social functioning of children with esophageal atresia. J Pediatr Surg, 1999;34:399-404.

8. Cortes RA, Keller RL, Townsend $T$, et al. Survival of severe congenital diaphragmatic hernia has morbid consequences. J Pediatr Surg, 2005;40:36-45.

9. Davis PJ, Firmin RK, Manktelow B, et al. Long-term outcome following extracorporeal membrane oxygenation for congenital diaphragmatic hernia: the UK experience. J Pediatr, 2004;144:309315.

10. Stolar CJ. What do survivors of congenital diaphragmatic hernia look like when they grow up? Semin Pediatr Surg, 1996;5:275-279.

11. Marven SS, Smith CM, Claxton D, et al. Pulmonary function, exercise performance, and growth in survivors of congenital diaphragmatic hernia. Arch Dis Child, 1998;78:137-142.

12. Trachsel $D$, Selvadurai $H$, Adatia $I$, et al. Resting and exercise cardiorespiratory function in survivors of congenital diaphragmatic hernia. Pediatr Pulmonol, 2006;41:522-529.

13. Trachsel $D$, Selvadurai $H$, Bohn $D$, et al. Long-term pulmonary morbidity in survivors of congenital diaphragmatic hernia. Pediatr Pulmonol, 2005;39:433-439.

14. Vanamo K, Rintala R, Sovijärvi A, et al. Long-term pulmonary sequelae in survivors of congenital diaphragmatic defects. J Pediatr Surg, 1996;31:1096-1100.

15. Friedman S, Chen C, Chapman JS, et al. Neurodevelopmental outcomes of congenital diaphragmatic hernia survivors followed in a multidisciplinary clinic at ages 1 and 3. J Pediatr Surg, 2008;43:1035-1043.

16. Muratore CS, Kharasch V, Lund DP, et al. Pulmonary morbidity in 100 survivors of congenital diaphragmatic hernia monitored in a multidisciplinary clinic. J Pediatr Surg, 2001;36:133-140.

17. Muratore CS, Utter $\mathrm{S}$, Jaksic $\mathrm{T}$, et al. Nutritional morbidity in survivors of congenital diaphragmatic hernia. J Pediatr Surg, 2001;36:1171-1176.

18. IJsselstijn $H$, Tibboel $D$, Hop WJ, et al. Long-term pulmonary sequelae in children with congenital diaphragmatic hernia. Am J Respir Crit Care Med, 1997;155:174-180.

19. Ravitch MM, Barton BA. The need for pediatric surgeons as determined by the volume of work and the mode of delivery of surgical care. Surgery, 1974;76:754-763.

20. Touwen BCL. Neurological development in infancy. Clinics in developmental medicine. London, United Kingdom: William Heinemann Medical Books; 1976.

21. Fredriks AM, van Buuren S, Burgmeijer RJ, et al. Continuing positive secular growth change in The Netherlands 1955-1997. Pediatr Res, 2000;47:316-323.

22. Fredriks AM, van Buuren S, Wit JM, et al. Body index measurements in 1996-7 compared with 1980. Arch Dis Child, 2000;82:107-112. 
23. Fredriks $A M$, van Buuren $S$, Jeurissen $S E$, et al. Height, weight, body mass index and pubertal development reference values for children of Turkish origin in the Netherlands. Eur J Pediatr, 2003;162:788-793.

24. Fredriks $A M$, van Buuren $S$, Jeurissen $S E$, et al. Height, weight, body mass index and pubertal development references for children of Moroccan origin in The Netherlands. Acta Paediatr, 2004;93:817-824.

25. Jobe AH, Bancalari E. Bronchopulmonary Dysplasia. Am J Respir Crit Care Med, 2001;163:17231729.

26. Baraldi $E$, de Jongste JC, on behalf of the Task Force. Measurement of exhaled nitric oxide in children, 2001. Eur Respir J, 2002;20:223-237.

27. Bruce RA, Kusumi F, Hosmer D. Maximal oxygen intake and nomographic assessment of functional aerobic impairment in cardiovascular disease. Am Heart J, 1973;85:546-562.

28. Karila C, de Blic J, Waernessyckle $\mathrm{S}$, et al. Cardiopulmonary exercise testing in children: an individualized protocol for workload increase. Chest, 2001;120:81-87.

29. Bergmeijer JH, Bouquet J, Hazebroek FW. Normal ranges of 24-hour pH-metry established in corrected esophageal atresia. J Pediatr Gastroenterol Nutr, 1999;28:162-163.

30. Bergmeijer JH, Hazebroek FWJ. Prospective medical and surgical treatment of gastroesophageal reflux in esophageal atresia. J Am Coll Surg, 1998;187:153-157.

31. Malmberg LP, Petays T, Haahtela T, et al. Exhaled nitric oxide in healthy nonatopic school-age children: determinants and heightadjusted reference values. Pediatr Pulmonol, 2006;41:635-642.

32. Cozzi DA, Zani A, Conforti A, et al. Pathogenesis of apparent lifethreatening events in infants with esophageal atresia. Pediatr Pulmonol, 2006;41:488-493.

33. Somppi E, Tammela O, Ruuska T, et al. Outcome of patients operated on for esophageal atresia: 30 years' experience. J Pediatr Surg, 1998;33:1341-1346.

34. Malmström K, Lohi J, Lindahl $\mathrm{H}$, et al. Longitudinal follow-up of bronchial inflammation, respiratory symptoms, and pulmonary function in adolescents after repair of esophageal atresia with tracheoesophageal fistula. J Pediatr, 2008;153:396-401.

35. Cozzi DA, Capocaccia P, Roggini M, et al. Respiratory status of infants with esophageal atresia. Pediatr Surg Int, 2001;17:92-96.

36. Kovesi T, Rubin S. Long-term complications of congenital esophageal atresia and/or tracheoesophageal fistula. Chest, 2004;126:915-925.

37. Dudley NE, Phelan PD. Respiratory complications in long-term survivors of oesophageal atresia. Arch Dis Child, 1976;51:279-282.

38. LeSouef PN, Myers NA, Landau LI. Etiologic factors in long-term respiratory function abnormalities following esophageal atresia repair. J Pediatr Surg, 1987;22:918-922.

39. Bohn D. Congenital diaphragmatic hernia. Am J Respir Crit Care Med, 2002;166:911-915.

40. Bos AP, Hussain SM, Hazebroek FW, et al. Radiographic evidence of bronchopulmonary dysplasia in high-risk congenital diaphragmatic hernia survivors. Pediatr Pulmonol, 1993;15:231-234.

41. Stanojevic S, Wade A, Lum S, et al. Reference equations for pulmonary function tests in preschool children: a review. Pediatr Pulmonol, 2007;42:962-972.

42. Taylor DR, Pijnenburg MW, Smith $A D$, et al. Exhaled nitric oxide measurements: clinical application and interpretation. Thorax, 2006;61:817-827.

43. Lally KP, Engle W. Postdischarge follow-up of infants with congenital diaphragmatic hernia. Pediatrics, 2008;121:627-632. 